\title{
Disminución de la participación de la población en organizaciones sociales durante los últimos trece ańos en Chile e implicaciones para la construcción de una política de planificación urbana más participativa ${ }^{1}$
}

Marie Geraldine Herrmann. Universidad Diego Portales, Santiago, Chile.

Annie van Klaveren. Universidad Alberto Hurtado, Santiago, Chile.

Resumen | La Política Nacional de Desarrollo Urbano 2014 de Chile declara como un objetivo la participación ciudadana "efectiva". Sin embargo, como muestra este artículo, la participación de la población en asociaciones voluntarias ha decrecido significativamente en Chile en general, y en la ciudad de Santiago en particular. La presente investigación procesa analíticamente las estadísticas sobre participación ciudadana contenidas en las encuestas CASEN 2000 y CASEN 2009, y en la Encuesta Santiago Cómo Vamos 2013, para concluir que la participación en organizaciones sociales disminuyó casi a la mitad en la ciudad de Santiago en los últimos trece años y que, en general, no existe interés por parte de la ciudadanía en instrumentos de planificación participativa. Por último, se identifican las implicaciones que tiene esta prescindencia en la construcción de una política de planificación urbana más participativa, y los desafíos que tal situación plantea.

PALABRAS ClAVE | participación ciudadana, planificación urbana, política urbana.

ABSTRaCt |The 2014 National Urban Development Policy of Chile defines among its objectives an "effective" public participation. However, as this article shows, participation in member-based organizations of diverse types has significantly decreased in Chile in general, and especially in the city of Santiago. The research conducted analyses data about participation in the national surveys CASEN 2000 and CASEN 2009, as well as in the survey Santiago Cómo Vamos 2013, demonstrating that participation in member-based organizations has decreased significantly in Santiago in the last thirteen years and that citizens lack interest in participatory urban planning tools. This article furthermore identifies the implications and challenges that these low levels of participation pose for building a more participatory urban planning policy.

KEY WORDS | citizen participation, urban planning, urban policy.

Recibido el 31 de enero de 2014, aprobado el 4 de octubre de 2014

E-mail: Geraldine Herrmann, geraldine.herrmann@udp.cl| Annie van Klaveren, annie.vanklaveren@gmail.com

Agradecimientos por su colaboración a Julieta Palma, socióloga, candidata PhD en Sociología, Universidad de Cambridge; y a Catalina Villalobos, arquitecta y magíster en Proyecto Urbano, Pontificia Universidad Católica de Chile. 


\section{Introducción}

En la reciente Política Nacional de Desarrollo Urbano ${ }^{2}$ desarrollada en Chile se señala que la planificación urbana requiere de una participación ciudadana "efectiva", entendida como "una condición proactiva" que debe ser garantizada por la institucionalidad (Ministerio de Vivienda y Urbanismo [MINvu], 2013, pár. 5.4.2). Pero ¿qué implica la noción de una participación ciudadana activa? ¿Y cómo es la participación ciudadana en Chile hoy?

La presente investigación tiene como objetivo analizar la participación de la población en organizaciones sociales en Chile durante el siglo xxi y sus implicaciones en la construcción de una política nacional de planificación urbana más participativa. Con este fin, se procesan las estadísticas sobre participación ciudadana contenidas en las encuestas de Caracterización Socioeconómica Nacional (CASEN) 2000 y 2009, y en Santiago Cómo Vamos: Primera Encuesta Ciudadana 2013: Percepción a la Gestión y Calidad de Vida de Santiago (en adelante, Encuesta Santiago Cómo Vamos 2013/scv 2013) , cuyos datos coinciden en que la participación de la población en asociaciones voluntarias ha disminuido significativamente en Chile en general, y en la ciudad de Santiago en particular durante los últimos trece años.

Este artículo se estructura en tres partes. La primera provee un marco teórico en relación con el concepto de participación como clave en el ejercicio activo de la ciudadanía en sociedades democráticas y estudia las variables que ayudan a entender los distintos niveles de participación. En la segunda parte se analiza descriptiva y comparativamente los datos contenidos en los módulos de participación incluidos en las encuestas CASEN 2000, CASEN 2009 y sCv 2013, desagregados según las variables de sexo, edad, ingreso, tipo de organización preferente, etcétera. Asimismo, se estudia la percepción de la población con respecto a mecanismos que permiten una participación más directa de la ciudadanía en la toma de decisiones de políticas urbanas. El artículo finaliza con las conclusiones que se pueden obtener a partir de los datos examinados e identifica las implicaciones y desafíos que los bajos niveles de participación en organizaciones sociales en Chile tienen para la construcción de una política de planificación urbana más participativa.

En la Política Nacional de Desarrollo Urbano chilena (PNDU) se señala que "una política no es una ley o un reglamento sino un documento dirigido al país en el cual se establecen principios, objetivos y líneas de acción con el fin de ayudar a mejorar la calidad de vida de todos" (MINvU, 2013, Introducción, sección B).

3 Santiago Cómo Vamos. Primera Encuesta Ciudadana 2013. Percepción a la gestión y calidad de vida de Santiago. Elaboración de la encuesta: Mesa técnica: ong Ciudad Viva; Fundación Avina; Laboratorio de Ciudad y Territorio (LCT), Universidad Diego Portales (UDP); Instituto de Investigación en Ciencias Sociales (ICSO), UdP. Organizaciones sociales: Fundación ProAcceso; Corporación sur; Federación Comunitaria de Organizaciones Comunales (FEMUC); Fundación Ciudadano Inteligente; Pulso; Acción (Asociación Chilena de Organismos No Gubernamentales). Disponible en http://www.drcom.udp.cl/encuesta_LCT2013.pdf 


\section{La participación ciudadana: \\ hacia una comprensión más amplia de la democracia}

Tanto el ideal como el concepto de democracia han dado lugar a numerosos debates sobre su significado, relevancia, requisitos y operacionalización. A pesar de que existe acuerdo general respecto de que un componente básico de un sistema democrático es que hombres y mujeres ejerzan sus derechos políticos, preguntas tales como qué otros elementos componen tal sistema, cómo se lo puede consolidar y fortalecer, y cómo se puede medir su calidad, han dado respuestas menos claras.

Frente a las definiciones procedimentales o normativas de democracia, algunos autores proponen un entendimiento más amplio, argumentando que tales enfoques no logran dar cuenta de las características y matices de los procesos de democratización que han atravesado muchos países en América Latina. En la interpretación que proponen, la democracia se refiere no solo a las reglas y procedimientos de un sistema político, sino que incluye la protección de los derechos económicos, sociales y culturales (DESC), componentes clave en el ejercicio de la participación y la cooperación. Esta conceptualización de la democracia no limita la participación a la expresión de una preferencia mediante el ejercicio de voto en una elección, sino que la entiende como un mecanismo mediante el cual los ciudadanos tienen una voz en las políticas que los afectan. Tal interacción entre ciudadanos y Estado puede indicar que, a pesar de que el sistema democrático de un Estado cumpla satisfactoriamente con criterios normativos, factores como la inequidad, exclusión, prácticas culturales, religión y tradiciones sociales, entre otros, afectan la función y modalidad mediante la cual los ciudadanos ejercen su ciudadanía.

Desde las observaciones de Tocqueville ([1835-1840] 2000) en Estados Unidos contenidas en Democracia en América sobre la relevancia de las normas cívicas y las asociaciones voluntarias, la literatura sobre el vínculo entre democracia y participación ha crecido exponencialmente. En democracias consolidadas, la visión de que la participación y la asociatividad contribuyen a fortalecer la democracia se considera sabiduría convencional. Sin embargo, en décadas recientes muchos autores han investigado sobre qué formas de asociatividad contribuyen a un avance de los valores democráticos en la sociedad y cómo lo hacen, entendiendo que no todas contribuyen de igual manera y que el impacto varía dependiendo del tipo de asociatividad (Putnam, Leonardi \& Nanetti, 1993; Fung, 2003; y Cohen \& Rogers, 1992). Esta discusión pone de relieve que la participación no es un fin en sí mismo, sino un medio por el cual los ciudadanos pueden ejercer voz y voto en aquellas decisiones que los afectan directamente, como lo hacen, por ejemplo, las políticas urbanas.

\section{Pero ¿de qué hablamos cuando hablamos de ciudadanía y participación?}

El concepto de democracia ha sido frecuentemente vinculado al de ciudadanía, dado que están estrechamente entrelazados. La democratización implica un cambio neto hacia un mayor foco en la ciudadanía (McAdams, Tarrow \& Tilly, 2001, p. 266). Y tal como sucede con el concepto de democracia, el de ciudadanía ha dado origen a un amplio debate sobre su significado, evolución y relevancia, y puede variar de un sujeto a otro, según sea el momento histórico y las características contextuales en que sea utilizado. 
El ensayo seminal de Marshall (1950) sobre ciudadanía ilustra cómo dicha noción puede ser deconstruida conceptualmente en diferentes elementos. Al respecto, Marshall identifica tres componentes principales del concepto, siendo estos el civil, el político y el social. El elemento civil se refiere a los derechos que son necesarios para la libertad individual, como el derecho al libre discurso, pensamiento y fe, o el derecho a la propiedad. El elemento político se refiere al derecho al ejercicio político de los individuos, tanto en cuanto ciudadanos como en su calidad de electores o candidatos. Finalmente, el elemento social se refiere a la gama de derechos relacionados con el bienestar económico y la integración social, que están posibilitados principalmente por la educación y los servicios sociales. Clave en el análisis de Marshall es la noción de que el entendimiento y la apropiación del concepto de ciudadanía están marcados por desarrollos históricos y, por tanto, reflejan diferentes problemáticas económicas y sociales.

El enfoque señalado es relevante para comprender la importancia del contexto en la definición del concepto de ciudadanía y, por consiguiente, cómo la definición del concepto mismo refleja desarrollos en la sociedad que se estudia. Sin embargo, esta aproximación analítica ha sido criticada por entender la ciudadanía como un estatus que es entregado a los individuos, y que existe solo en la medida en que sus derechos son reconocidos y respetados. ¿Qué sucede, entonces, en el caso de individuos o grupos que son excluidos social y económicamente y cuyos derechos no han sido reconocidos o respetados de la misma manera que los de otros grupos más favorecidos o influyentes?

Debates más recientes se han focalizado en la práctica de la ciudadanía más que en su definición conceptual, postulando así una noción más activa y dinámica de ella (Lister, 1998, p. 6). Esta perspectiva apunta a un cambio desde una conceptualización que entiende a los individuos como agentes pasivos hacia otra en la cual los individuos son agentes activos, e incluye el análisis de los mecanismos de inclusión social y de la forma en que grupos normalmente excluidos se organizan y movilizan como un colectivo. La noción de "ciudadanía activa" surge como un concepto más dinámico e inclusivo, referido a la forma mediante la cual diferentes grupos articulan y renegocian sus derechos y aspiraciones, y a cómo los intereses locales se articulan con intereses globales. Esta concepción se centra en el "derecho a tener derechos", una forma universal de ciudadanía que permite a grupos excluidos encontrar un lenguaje común, no necesariamente articulado desde instituciones como partidos políticos, sindicatos o el Estado. Así, grupos excluidos ejercen la ciudadanía de una manera activa para reafirmar su lucha por derechos, por reconocimiento o por satisfacer sus aspiraciones democráticas. Ejemplos recientes en el caso de Chile son las protestas estudiantiles de 2011-2013 y la irrupción del movimiento social de Aysén.

En América Latina, la noción de ciudadanía emergió en los años setenta y ochenta vinculada a procesos de democratización, en el marco de la articulación de demandas políticas y sociales y la apertura de espacios en las democracias emergentes. En el caso de Chile, la afirmación del concepto de ciudadanía siguió una lógica neoliberal, enfocada en el individuo, no en el colectivo, y con énfasis en su integración a la economía de mercado. Dado que muchos bienes públicos son provistos a través del mercado como objetos de consumo privado -algunos ejemplos 
son la educación, la salud, la vivienda-, el término "participación ciudadana" fue utilizado en los años noventa comúnmente en dos sentidos: lograr el involucramiento de los ciudadanos en programas públicos destinados a facilitar o mediar en el acceso a los bienes ofrecidos, y ello a través de una modalidad de información consultiva; o lograr la validación de tales programas por parte de la ciudadanía. A pesar de que la participación en dichos programas estatales es descrita frecuentemente como estrategia dirigida a empoderar individuos a través del ejercicio de su ciudadanía, las iniciativas resultantes no han implicado necesariamente un aumento en la capacidad de los individuos de influenciar las políticas que los afectan, puesto que apuntan más bien a establecer modalidades de consulta y validación.

En su crucial artículo de 1969, Arnstein analiza el concepto de participación y sus modalidades. En él, la autora desarrolla una tipología de modalidades de participación en instancias de toma de decisiones, donde se destacan tres categorías, que van de menor a mayor participación. La primera, aquella de "no participación", incluye los niveles de manipulación y de terapia, que substituyen instancias legítimas de participación y que tienen el objetivo de "educar" a los participantes. La segunda categoría es aquella de tokenismo (o simbolismo), y los diferentes niveles son los de información, consulta y apaciguamiento. En los tres niveles de tokenismo, los ciudadanos son escuchados, pero no tienen el mandato o poder necesarios para asegurar que sus visiones sean consideradas y debidamente reflejadas en las políticas o programas estatales. Estos, como resultado, frecuentemente no logran los objetivos promulgados en cuanto a fomentar el empoderamiento ciudadano. La tercera categoría y aquella de mayor participación, es la de "poder ciudadano". Esta incluye los niveles de partenariados, delegación de poder y control ciudadano, y permite a los ciudadanos no solo ser escuchados, sino negociar y desempeñar un rol principal en las instancias de toma de decisiones de los procesos o políticas que los afectan. Un buen ejemplo de la categoría de poder ciudadano en la planificación urbana se da en los presupuestos participativos iniciados en la década de los noventa en Porto Alegre, Brasil.

Cuarenta años después, el término "participación ciudadana" -entendido también como participación local- sigue siendo una de las expresiones de moda en organizaciones no gubernamentales (ONG), organizaciones internacionales y programas gubernamentales. De hecho, el Banco Mundial comenzó a promover activamente enfoques participativos a comienzos de los noventa. Así, definió participación como "un proceso mediante el cual los actores sociales influencian y comparten el control sobre iniciativas de desarrollo y las decisiones y recursos que las afectan" (World Bank, 1994, p. i). También definió una tipología de los diferentes niveles de participación, empezando en su nivel más bajo, difusión de información, al más alto, empoderamiento (p. 12). Esta visión de la participación, comúnmente utilizada, es entendida como un medio para empoderar a individuos, facilitándoles las herramientas necesarias para lograr consensos y llevar a cabo las acciones necesarias para mejorar sus circunstancias sociales, económicas y medioambientales. Así, la participación se volvió habitual en programas de cooperación de países donantes y de programas gubernamentales. Pero las voces críticas no demoraron en hacerse escuchar. 
Una objeción común es que la visión de participación señalada muchas veces es simplista y obscurece dinámicas más complejas, que requieren de mayor reflexión teórica. En un libro en que analizan la teoría y la práctica de la participación ciudadana, Nelson y Wright (1995) cuestionan el concepto de empoderamiento, frecuentemente utilizado como sinónimo de participación ciudadana, destacando la contradicción inherente al hecho de que los ciudadanos sean empoderados gracias a programas implementados "de arriba hacia abajo", cuyos administradores bien pueden mantener el control de los mismos a través del encauzamiento deliberado de la participación ciudadana. En esta línea, Guijt y Shah (1998, pp. 7-12) argumentan que la articulación estática y a veces ingenua del concepto de comunidad -utilizado en el contexto de programas participativos- esconde relaciones de poder, jerarquías sociales, y que poca atención se pone, por ejemplo, en analizar dentro de dichas comunidades la discriminación basada en edad, sexo, religión, etcétera. La manera "simplista" en la cual se habla de comunidad ha contribuido a generar entusiasmo alrededor de programas que la incluyen como eje articulador. El hecho de que la participación sea concebida como un continuo, que va de niveles de menor participación a mayores niveles de participación y empoderamiento, asume que un nivel lleva automáticamente al siguiente y que los ciudadanos van a estar rápidamente dispuestos a comprometerse a participar en lo que pueden ser procesos tediosos y con considerables costos de oportunidad. En esta línea, Font, Blanco, Gomá y Jarque (2000) argumentan que la esperada explosión participativa no ha sido tal y que aun si hay una demanda creciente de participación, esta tiene límites y no puede ser extendida de forma indefinida ${ }^{4}$.

\section{Variables que ayudan a entender los niveles de participación}

Diversos estudios han tenido como objetivo identificar aquellos elementos contextuales que pueden fomentar o inhibir la participación. Según Curtis, Baer y Grabb (2001), a pesar de que la evidencia empírica sigue siendo limitada y que los argumentos teóricos para entender las diferencias entre países en términos de participación y asociativismo no están del todo desarrollados (p. 785), diversos estudios de

Mohan y Stokke (2000) señalan que la participación suele ser utilizada con fines políticos, sea para validar el modelo económico o para cuestionarlo. Así, la "nueva derecha” ve el Estado como una barrera para el crecimiento económico y postula que lo deseable es transferir la provisión de servicios sociales a organizaciones de la sociedad civil, para gradualmente reducir el aparato estatal. En esta visión, el concepto de participación es articulado "de arriba hacia abajo", esquema según el cual la participación es canalizada cuidadosamente y el empoderamiento -la integración de los individuos en la economía de mercado- se logra sin confrontaciones ni alterar en lo más mínimo el statu quo (Mohan \& Stokke, 2000, pp. 248-249). La “nueva izquierda", en cambio, ve la participación como un medio para movilizar a los ciudadanos contra las acciones desempoderadoras del Estado y del mercado. Así, la participación "de abajo hacia arriba” tiene como objetivo desafiar los intereses hegemónicos y prevalentes, buscando una transformación estructural para lograr una democracia de carácter radical, fin que puede ser alcanzado por el florecimiento de movimientos sociales diversos. De esta manera, se puede ver que, a pesar de que desde distintos lados del espectro político se articulan concepciones diferentes de la participación, ambas le atribuyen un rol importante, sea como instrumento destinado a consolidar o legitimar un sistema, o como herramienta para alterar el statu quo y cambiar estructuras inequitativas. 
carácter comparativos dan cuenta de cuatro elementos que inciden positivamente en los niveles de participación. Al respecto, se mencionan los siguientes:

- Nivel de desarrollo económico. Varios autores (Almond \& Verba, 1963; Lipset, 1994; entre otros) argumentan que mientras más desarrollada es una sociedad, mayores son sus niveles de asociativismo, fomentados por mayores niveles de ingreso y educación y por la emergencia de una clase media activa. Algunos autores han precisado que la inequidad reduce la participación (Uslaer \& Brown, 2005), lo que indicaría que no solo el nivel de desarrollo económico tiene influencia, sino también la forma en que está distribuida la riqueza en una sociedad.

- Modelo de desarrollo. Algunos autores han argumentado que, además del nivel de desarrollo económico, el modelo mediante el cual este se logra tiene diferentes impactos en los niveles de participación. Por ejemplo, Curtis et al. (2001) aluden al trabajo de Janoski (1998), quien concluye que en economías liberales y sociales, los niveles de participación y asociativismo suelen ser más altos que en otros modelos. En economías liberales, las asociaciones se forman para remplazar al Estado en ámbitos en los que la provisión de ciertos servicios es escasa o inexistente. En economías sociales, el Estado puede proveer financiamiento para la formación de asociaciones como una forma de fomentar la cohesión social.

- Nivel de estabilidad democrática. Se ha argumentado que niveles elevados de estabilidad democrática brindan más tiempo para que las asociaciones se desarrollen y consoliden y para que los ciudadanos aumenten la confianza entre sí, lo que se traduce en mayor cooperación y reciprocidad. También se ha determinado que los ciudadanos de democracias establecidas tienen mayor apego a valores democráticos y, por tanto, serían más proclives a formar diferentes tipos de asociaciones y/o participar en ellas.

- Impacto de tradiciones religiosas. La literatura existente sugiere que sociedades con altos niveles de protestantismo son más proclives a fomentar asociatividad. Tocqueville observó en Estados Unidos el rol pivotal de la religión no solo en la promoción de asociativismo, sino también en la política. Aunque aquí muy simplificado, el argumento es que el protestantismo fomenta que los individuos formen y participen en organizaciones sociales, en lugar de depender del Estado para la provisión de ciertos servicios. La estructura organizacional de las instituciones protestantes también fomentaría tal tendencia, al aparecer estas como más igualitarias y participativas cuando comparadas, por ejemplo, con las del catolicismo (Verba et al., 1995; Lipset, 1994). En un análisis de treinta y tres países democráticos, Curtis et al. (2001) encontraron que los países protestantes tienen mayores niveles de asociativismo, pero que las sociedades donde conviven diferentes formas de cristianismo también tienen niveles elevados de participación en organizaciones sociales. 
De acuerdo con la literatura sobre el tema, los elementos señalados anteriormente pueden tener impacto en los niveles de participación a escala nacional. En esta misma línea, Aguilar y Navarro (2000) postulan que a pesar de que a menudo se menciona el nivel local o municipal como el más idóneo para llevar a cabo experiencias de participación y de profundización de la democracia representativa, la existencia de trabas estructurales relacionadas con la naturaleza de los sistemas democráticos y las preferencias de los actores sociales en dichos sistemas complejizan la participación ciudadana. Otros elementos que pueden complejizar la participación ciudadana y que no han sido estudiados cabalmente en este sentido, son las tradiciones sociales y culturales. Por ejemplo, en países mediterráneos o latinoamericanos, la familia ocupa un lugar central en las relaciones sociales, y en muchas ocasiones la utilización de lazos familiares para satisfacer necesidades económicas o para buscar solución a problemas puede inhibir la participación en asociaciones voluntarias. Asimismo, en países con una cultura clientelista la participación quizá sea menor, dado que los ciudadanos pueden estar más interesados en forjar relaciones de cooperación verticales, por ejemplo con agentes políticos, en lugar de con pares, por ejemplo con vecinos. A pesar de que no hay suficiente evidencia empírica hasta la fecha sobre estas hipótesis, ellas pueden seńalar nuevas avenidas de investigación sobre las causas, niveles y modalidades de participación, sobre todo en países en vías de desarrollo.

\section{Participación de la población en organizaciones sociales en Chile y en el Gran Santiago durante los últimos trece ańos}

Habiendo establecido la importancia de la participación y de las organizaciones sociales para el ejercicio de la democracia en términos generales, esta sección tiene como objetivo estudiar la participación de la población en organizaciones sociales en Chile y el Gran Santiago durante el siglo xxi. Se propone examinar las posibles variaciones en aquellos elementos identificados como relevantes en la literatura estudiada, y revisar otros que pueden desempeñar un rol importante en el caso de esta investigación, como son el nivel de ingreso, género, edad y tipo de organización social preferente. El propósito de este análisis es obtener el más completo y matizado cuadro posible sobre la participación en Chile en general, y en Santiago en particular.

Con el fin señalado, la presente investigación procesa y analiza los datos contenidos en los módulos de participación de las encuestas CASEN 2000, CASEN 2009 y sCv 2013. Dado que en Chile no existen encuestas sistemáticas sobre la participación en una gama amplia de organizaciones sociales de membrecía voluntaria (referidas en este artículo también como asociaciones sociales o voluntarias), no es tarea fácil obtener datos relevantes y actualizados que permitan analizar la participación en Chile. Considerando esta limitación, este artículo utiliza para el análisis, por un lado, las encuestas CASEN 2000 y 2009, que en dichos años incluyeron un módulo para medir la participación; la comparación entre estas dos encuestas permite esbozar un mejor entendimiento sobre el nivel y evolución de la participación en asociaciones voluntarias a escala nacional. Por otro lado, se utiliza la scv 2013, que 
permite evaluar la participación en la ciudad de Santiago con datos más recientes y con una mayor focalización en las percepciones de los ciudadanos sobre la participación en la planificación urbana.

La comparación de los datos de la encuesta CASEN (2000 y 2009) con aquellos disponibles para la ciudad de Santiago a través de la scv 2013 tiene limitaciones metodológicas, dadas las diferencias entre dichas mediciones en términos de escala, muestra, preguntas y foco. Por lo mismo, en la mayor parte de las variables de interés, los datos son tratados de manera aislada. Cuando se los analiza comparativamente, se trabaja de manera cautelosa y con el propósito de evaluar la participación con datos recientes y obtener una perspectiva de más largo alcance en el tiempo, lo que permite identificar tendencias generales, aunque no exactas. Así, la investigación realizada mediante la comparación de las tres encuestas permite establecer como tendencia general que en Chile, y en el Gran Santiago en particular, la participación de la población en asociaciones voluntarias ha disminuido significativamente entre los años 2000 y 2013.

La encuesta CASEN incluyó un módulo sobre participación únicamente en los años 2000 y 2009, y al analizar comparativamente ambos años ${ }^{5}$, se puede ver que la participación en organizaciones sociales ${ }^{6}$ de la población de 18 años y más en Chile ha disminuido en más de un tercio en solo nueve ańos. Mientras que en el año 2000 , un $30,7 \%$ de los encuestados declaró participar en al menos una asociación voluntaria, el porcentaje en el ańo 2009 fue de 20,1\% (gráfico 1).

Nota metodológica: la encuesta CASEN 2000 consideró 19 organizaciones sociales en sus categorías, mientras que la versión 2009 consideró solamente 15. Asimismo, la encuesta CASEN 2000 consideró únicamente una organización ( ¿Participa Ud. en alguna de las siguientes organizaciones? [Señale a la que le dedica mayor tiempo])” (Preg. 15), y la encuesta CASEn 2009 permitió escoger dos organizaciones preferentes ( $¿$ "Participa actualmente en alguna organización o grupos organizados”?) (Preg. 18a y 18b). A pesar de esta diferencia, es posible comparar el nivel de participación, ya que en el caso de la encuesta CASEN 2009, el indicador de participación se construyó sobre la base de las personas que señalaron que participaban en alguna organización en la primera preferencia.

6 La encuesta CASEN 2000 considera como organizaciones sociales las siguientes: Organización de vecinos/Unión comunal; Comité de Adelanto; Centro de Madres/Talleres de mujeres/ Talleres laborales; Organización Juvenil; Club Deportivo y recreativo; Organización artística y cultural; Política (Partidos políticos); Religiosa; Beneficencia y/o Voluntariado; Asociación Gremial/Colegios Profesionales/Agrupación de empresarios; Grupos de Salud; Organizaciones de Adultos Mayores; Organizaciones de Personas con Discapacidad; Organizaciones Solidarias; Comités de allegados/Comité habitacionales; Organizaciones de Padres y Apoderados; Comités de agua potable/Comunidades de agua; Sindicatos; y Otra. La encuesta Casen 2009 reduce las opciones y considera como organizaciones voluntarias las siguientes: Organización de vecinos; Club deportivo recreativo; Centro de alumnos/Centro de padres y apoderados; Organización voluntariado o beneficencia; Colegio profesional/Asociación gremial; Sindicato; Partidos políticos; Asociación productiva; Asociación o comunidad indígena; Asociación de personas con discapacidad; Organización de adultos mayores; Organización juvenil; Grupo religioso; Centro de madres/Talleres de mujeres/Grupo de mujeres; y Agrupación cultural o creación artística. 


\section{GRÁFICO I | Nivel de participación en organizaciones sociales} (total país, población de 18 años y más)

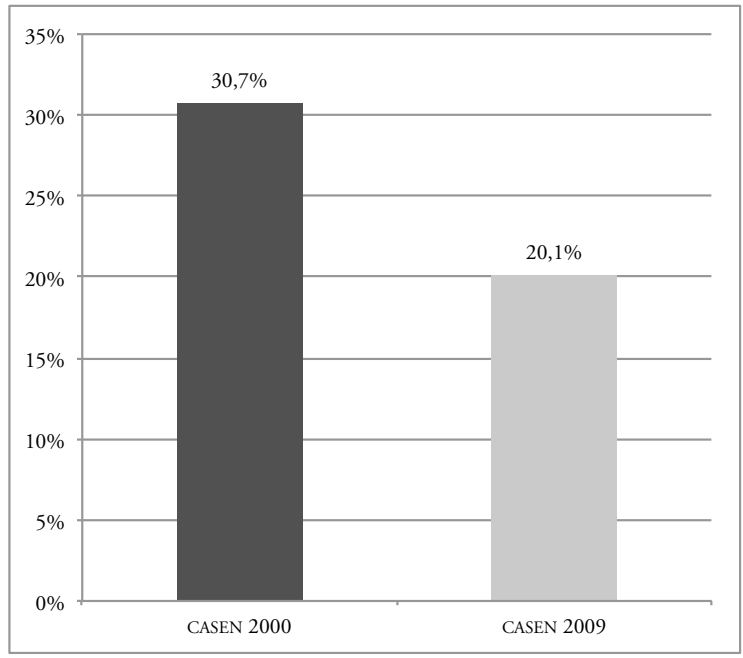

FUENTE ENCUESTAS CASEN 2000 Y 2009, MINISTERIO DE DESARROLLO SOCIAL, DIVISIÓN SOCIAL

Asimismo, al comparar los datos sobre participación de las encuestas CASEN 2000, CASEN 2009 y sCv 2013 en la población de 18 años y más en el Gran Santiago ${ }^{7}$, se corrobora la tendencia a la disminución de la participación de la población en organizaciones sociales o grupos organizados ${ }^{8}$ (gráficos 2 y 3). Mientras en el ańo 2000, $23,8 \%$ de los santiaguinos declaró participar en al menos una organización social, el porcentaje en el año 2009 fue de 14,5\%, y en el ańo 2013 de solo 12,4\%. Así, la participación en organizaciones sociales en la ciudad de Santiago se ha reducido a casi la mitad en solamente trece años.

Al comparar los datos del Gran Santiago con el nivel de participación a nivel nacional, esta tendencia se corrobora, dado que tanto en el país como en la capital, la participación está declinando.

7 Nota metodológica: Para asimilar el universo de encuestados de CASEN a sCV, se seleccionan los encuestados de 18 ańos y más que habitan en el Gran Santiago (mismas comunas que incluye encuesta SCV, esto es, todas las comunas de la provincia de Santiago más Puente Alto y San Bernardo). Se trabaja con las respuestas de las preguntas P18 (CASEn 2000) y T18A (CASEn 2009) y la pregunta P33 (scv 2013) (“`Participa usted en alguna organización social de su barrio o comuna?").

8 La sCv 2013 considera como organizaciones sociales las siguientes doce categorías: Organización de vecinos (Junta de Vecinos, Unión comunal); Club deportivo recreativo; Centro de alumnos, Centro de padres y apoderados; Organización voluntariado o beneficencia; Sindicato, Colegio Profesional o Asociación Gremial; Partidos políticos u organizaciones políticas; Asociación productiva (microempresarios, agrícola, de pescadores); Organización juvenil; Grupo religioso (movimientos pastorales, grupo de Iglesia); Organizaciones ciudadanas (indígena, juvenil, adulto mayor, etcétera); Comunidad o grupo virtual; y Agrupación cultural o creación artística. 
GRÁFICO 2 | Nivel de participación en organizaciones sociales (Gran Santiago, población de 18 años y más)

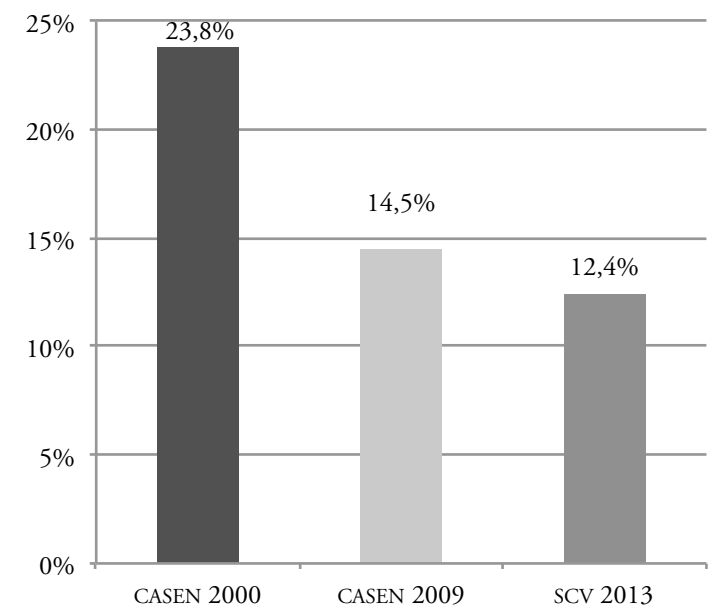

FUENTE ENCUESTAS CASEN 2000 Y CASEN 2009, MINISTERIO DE DESARROLLO SOCIAL, DIVISIÓN SOCIAL; Y SANTIAGO CÓMO VAMOS. PRIMERA ENCUESTA CIUDADANA 2OI3. PERCEPCIÓN A LA GESTIÓN Y CALIDAD DE VIDA DE SANTIAGO

GRÁFICO 3 | Nivel de participación en organizaciones sociales (total país y Gran Santiago, población de 18 años y más)

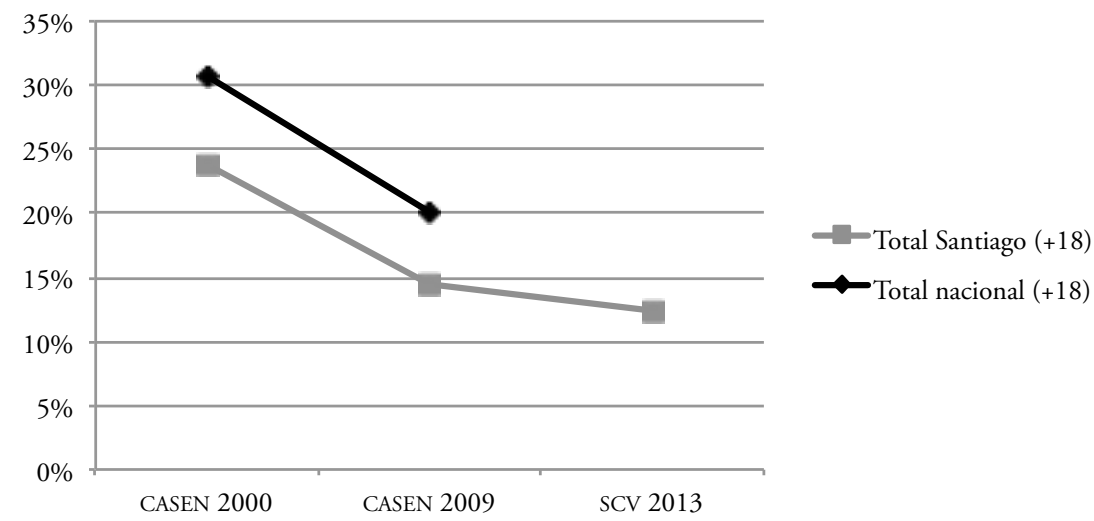

FUENTE ENCUESTAS CASEN 2000 Y CASEN 2009, MINISTERIO DE DESARROLLO SOCIAL, DIVISIÓN SOCIAL; Y SANTIAGO CÓMO VAMOS. PRIMERA ENCUESTA CIUDADANA 2OI3. PERCEPCIÓN A LA GESTIÓN Y CALIDAD DE VIDA DE SANTIAGO

Para comprender mejor las tendencias en el nivel de participación -tanto a nivel nacional como en el Gran Santiago-, a continuación se analizarán posibles variables que, de acuerdo con la literatura examinada, pueden incidir en su aumento o disminución. Por su parte, esta investigación añade al estudio otras variables para obtener 
una imagen más completa de las características de la participación en Chile. Lo primero que interesa entender es si hay diferencias significativas en el nivel de participación en zonas urbanas comparadas con las rurales. En general, las zonas urbanas poseen mejores servicios que las rurales y, por tanto, el incentivo para participar en organizaciones sociales puede ser menor. ¿Gatilla esto niveles diferentes de participación? Asimismo, en un país altamente centralizado como Chile, es probable que los habitantes de zonas rurales participen en organizaciones sociales para ejercer presión sobre autoridades locales.

GRÁfICO 4 | Nivel de participación en organizaciones sociales por zona rural y urbana (total país, población de 18 años y más)

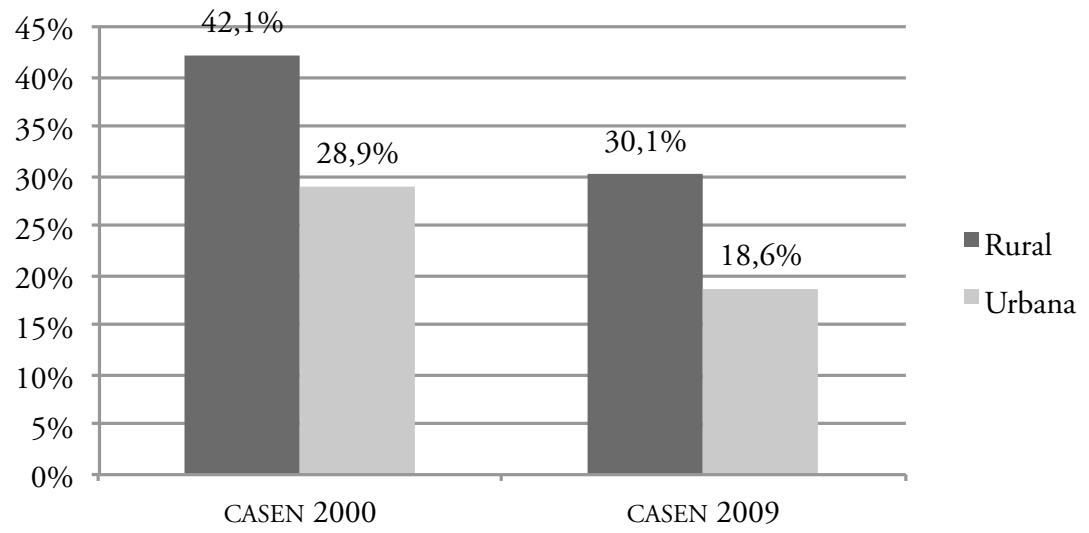

FUENTE ENCUESTAS CASEN 2000 Y CASEN 2009, MINISTERIO DE DESARROLLO SOCIAL, DIVISIÓN SOCIAL

Como muestra el gráfico 4, efectivamente los niveles de participación en zonas rurales son mayores que en las urbanas, aunque su declinación fue algo más pronunciada en ellas entre 2000 y 2009 de lo que ha sido en las ciudades. Y así como el nivel de participación es diferente en zonas rurales y urbanas, a escala regional también se observan diferencias considerables. De acuerdo con los resultados de la encuesta CASEN 2009, las cuatro regiones con niveles más altos de participación son aquellas de Los Ríos (30,5\%), Los Lagos (28,3\%), La Araucanía (28,2\%), y Bío-Bío (26,2\%), todas ubicadas en el sur del país y con un alto porcentaje de población indígena?.

\section{Relación entre ingreso y participación en Chile}

En la literatura académica sobre la participación se considera que el nivel de ingreso tiene un peso importante en el grado de participación (Burnham, 1972). Normalmente, aquellos que poseen ingresos más altos tienen incentivos más fuertes para participar, dado que es más probable que puedan ejercer mayor influencia en los ámbitos en que desean incidir y, por tanto, ver resultados. También es más

9 Con la excepción de Los Lagos, todas las regiones con mayores niveles de participación tienen también un alto porcentaje de hogares en situación de pobreza. Datos disponibles en el Ministerio de Vivienda y Urbanismo, en www.observatoriourbano.cl, basados en información del censo 2002. 
probable que aquellos de mayor ingreso se sientan más representados por algún partido político. Así, se deduce que el grado de inequidad socioeconómica a nivel nacional puede tener un impacto negativo en la participación. En un estudio llevado a cabo en Estados Unidos sobre la relación entre inequidad, confianza y participación, Uslaner y Brown (2005) argumentan que en países con altos niveles de inequidad, los ciudadanos de menores ingresos pueden tener menos incentivos para participar y, por tanto, optar por no hacerlo. Un menor nivel de confianza entre ciudadanos, como puede suceder, por ejemplo, en sociedades con altos niveles de inequidad, también puede tener efectos negativos en la participación (Uslaner \& Brown, 2005, p. 2). Esta realidad se refleja en la frase frecuentemente citada en estudios sobre el tema, según la cual "la falla en el cielo de la pluralidad es que el coro canta con un acento de clase alta" (Schattschneider, 1960, p. 35, citado en Fung, 2003, p. 524 $)^{10}$.

En este contexto, es interesante ver que, en Chile, la participación en asociaciones voluntarias no parece estar determinada por el nivel de ingreso. De hecho, el análisis de los datos de las encuestas CASEN ${ }^{11}$ en este tema arroja resultados sorprendentes, ya que el año 2009 la participación fue más homogénea a través de grupos con diferentes niveles de ingreso (organizados en quintiles) que en el ańo 2000, aunque cabe notar que esta diferencia tampoco fue substantiva dicho año (gráfico 5$)^{12}$. Por ejemplo, en el año 2000, el quintil con mayor nivel de participación es el 1 (correspondiente al $20 \%$ de la población con menores ingresos) y el con menor participación es el 5 (correspondiente al 20\% de mayores ingresos), siendo la diferencia entre ambos de 5,8 puntos porcentuales. En cambio, el año 2009, la diferencia entre el quintil con mayor nivel de participación (el 1) y el con menor (el 4) se acorta a tan solo 1,7 puntos porcentuales, lo que implica que el nivel de participación baja significativamente en todos los quintiles, resultando en un nivel de participación más homogéneo entre ellos.

Al comparar el nivel de participación por quintil de ingreso a nivel nacional con el del Gran Santiago, se observan diferencias interesantes. Por ejemplo, si el año 2009 a nivel nacional el quintil 1 es el que tiene mayor participación en organizaciones sociales, en el Gran Santiago es el quintil 1 el que participa menos y el quintil 5 el que participa más (gráfico 6) ${ }^{13}$. El hecho de que la participación sea más alta en un grupo de mayor ingreso es consistente con la literatura académica, que establece que aquellos que poseen mayor ingreso tienen mayores incentivos para participar, ya

10 Referencia a E. E. Schattschneider, The semi-sovereign people (Nueva York: Holt, Rinehart \& Winston, 1960).

11 Nota metodológica: se trabajó con el quintil de ingreso autónomo nacional (excluye servicio doméstico puertas adentro y su núcleo).

12 Para medir la distribución del ingreso entre los hogares, estos son clasificados en deciles (quintiles), de acuerdo con el ingreso autónomo per cápita percibido por el hogar; luego se estima la participación porcentual de los ingresos de los hogares de cada decil (quintil) en el total de ingresos del total de hogares del país. Fuente: Observatorio Social, Ministerio de Desarrollo Social, Preguntas Frecuentes, Encuesta CASEn. Disponible en www.ministeriodesarrollosocial. gob.cl/casen/preguntas_frecuentes.html\#6

13 Nota metodológica: se trabajó con el quintil de ingreso autónomo regional (excluye servicio doméstico puertas adentro y su núcleo). 
que tienen mayores posibilidades de ejercer influencia y confianza de percibir algún resultado. Sin embargo, hace falta más investigación y sobre todo datos actualizados para establecer las causas de la diferencia observada en el nivel de participación en organizaciones sociales por quintil a nivel nacional y en el Gran Santiago.

GRÁfICO 5 Nivel de participación en organizaciones sociales por quintil de ingreso (total país, población de 18 años y más)

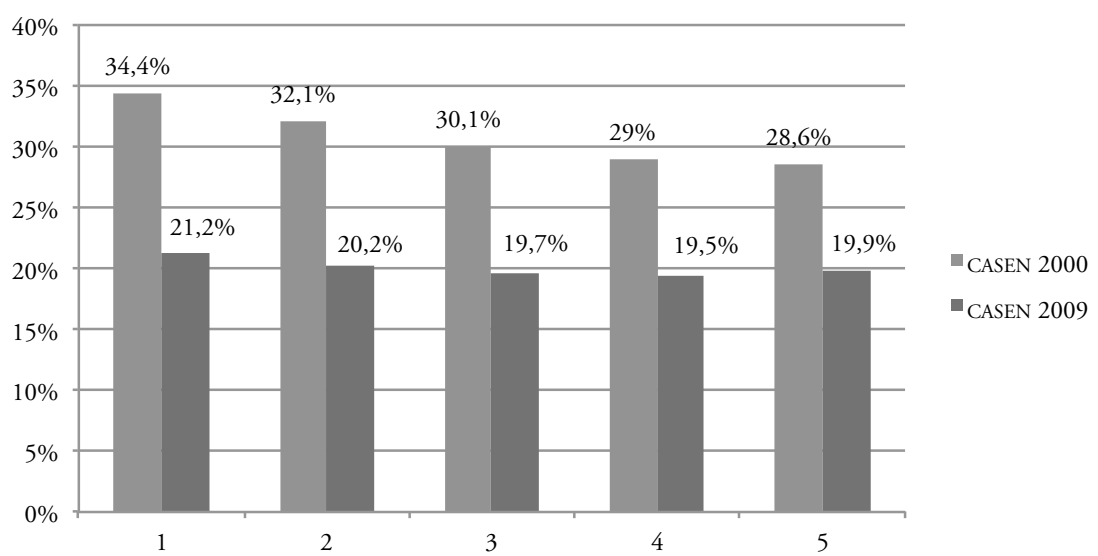

FUENTE ENCUESTAS CASEN 2000 Y CASEN 2009, MINISTERIO DE DESARROLLO SOCIAL, DIVISIÓN SOCIAL

GRÁfICO 6 Nivel de participación en organizaciones sociales por quintil de ingreso (Gran Santiago, población de 18 años y más)

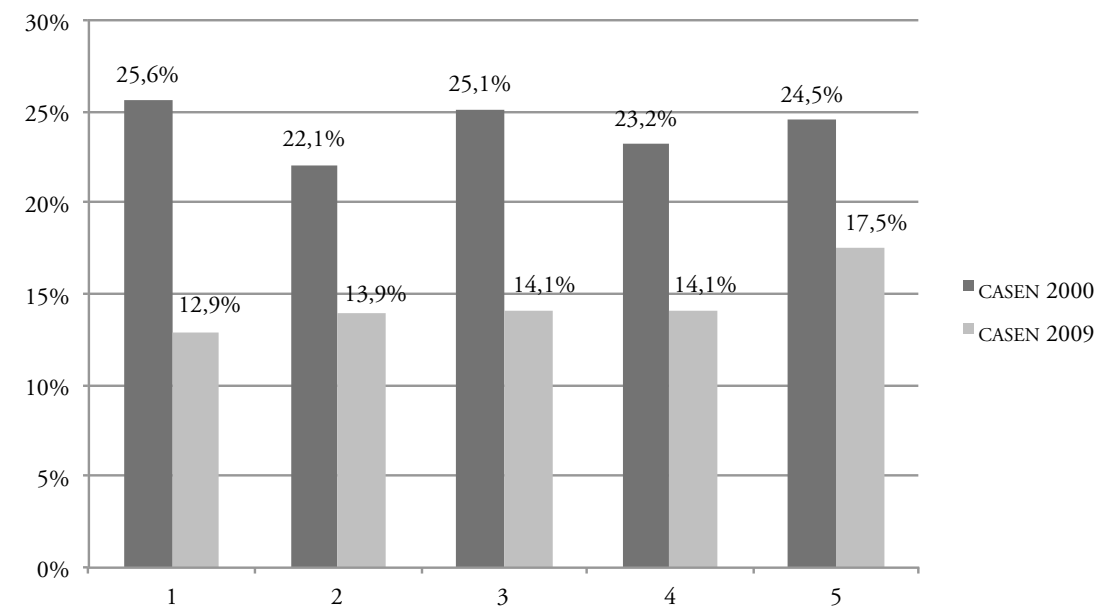

FUENTE ENCUESTAS CASEN 2000 Y CASEN 2009, MINISTERIO DE DESARROLLO SOCIAL, DIVISIÓN SOCIAL 


\section{Relación entre género y participación en el Gran Santiago}

El impacto del sexo sobre la participación también ha captado atención académica. ¿Pueden observarse diferencias significativas en la forma en que hombres y mujeres participan en Chile? En un estudio sobre género y participación ciudadana en los Estados Unidos, Schlozman, Burns, Verba y Donahue (1995) observan que, al contrario de argumentos previos sobre el tema, según los cuales las mujeres suelen participar más en asociaciones voluntarias, las diferencias en los niveles de participación de hombres y mujeres en asociaciones voluntarias no son significativas. Según este estudio, hay mayores similitudes que diferencias tanto en los niveles de participación de hombres y mujeres, como en los asuntos que los motivan a participar y en la gratificación que obtienen de dicha participación.

Los datos arrojados por las encuestas CASEN 2000 y CASEN $20099^{14}$ muestran que las mujeres tienen un nivel de participación más alto que los hombres, aunque la diferencia no es tan pronunciada (cuadro 1). Sin embargo, hay diferencias más significativas en el tipo de organización en el cual participan hombres y mujeres, consistentes con roles de género tradicionales. Por ejemplo, el nivel de participación de hombres es significativamente mayor que el de mujeres en organizaciones influyentes, como son los sindicatos, las asociaciones gremiales y los partidos políticos. Todas estas agrupaciones tienen puntos de acceso directos al sistema político y relaciones verticales de organización entre los miembros. Las mujeres, en cambio, participan en mayor medida en centros de orientación comunitaria, como son los de caridad o de beneficencia, o de alumnos o de padres y apoderados, y los de adultos mayores. Estas organizaciones están frecuentemente orientadas a satisfacer una necesidad de bienestar allí donde los servicios del Estado normalmente son débiles, y favorecen un patrón más horizontal de relaciones entre sus miembros. Cabe seńalar, sin embargo, que en algunos casos la marcada diferencia de participación entre hombres y mujeres en algunas organizaciones políticamente influyentes (predominio de hombres) disminuyó en el Gran Santiago entre 2000 y 2009.

Estos datos son en gran medida coincidentes con los de la encuesta Santiago Cómo Vamos 2013, que indica que la participación de mujeres es significativamente más alta en organizaciones de vecinos, centros de padres y apoderados, organizaciones de beneficencia, y voluntariado y grupos religiosos.

14 Nota metodológica: en el caso de la encuesta CASEN 2000, se escogieron aquellas organizaciones sociales que se consideran claves para entender cómo se distribuye la participación en organizaciones sociales entre hombres y mujeres. En el caso de la encuesta CASEn 2009 se considera únicamente la organización social que se menciona como primera opción de organización preferente. 
CUADRO I | Distribución de la población que participa en organizaciones sociales por sexo según tipo de organización (Gran Santiago, población de 18 años y más, en porcentajes)

\begin{tabular}{|c|c|c|c|c|c|c|}
\hline \multirow{2}{*}{$\begin{array}{l}\text { TIPO DE ORGANIZACIÓN } \\
\text { PREFERENTE }\end{array}$} & \multicolumn{3}{|c|}{ CASEN 2000} & \multicolumn{3}{|c|}{ CASEN 2009} \\
\hline & HOMBRES & MUJERES & & HOMBRES & MUJERES & \\
\hline $\begin{array}{l}\text { Organización de vecinos (Junta de } \\
\text { vecinos, Unión comunal) }\end{array}$ & 40,8 & 59,2 & 100 & 36,5 & 63,5 & 100 \\
\hline Club deportivo y recreativo & 77,3 & 22,7 & 100 & 84,7 & 15,3 & 100 \\
\hline $\begin{array}{l}\text { Centro de alumnos, Centro de padres y } \\
\text { apoderados }\end{array}$ & $* 22,1$ & *77,9 & 100 & 30,8 & 69,2 & 100 \\
\hline $\begin{array}{l}\text { Organización voluntariado o } \\
\text { beneficencia }\end{array}$ & 45,1 & 54,9 & 100 & 40,1 & 59,9 & 100 \\
\hline $\begin{array}{l}\text { Colegio profesional/Asociación } \\
\text { gremial/Agrupación de empresarios }\end{array}$ & 64,4 & 35,6 & 100 & $* * 54,0$ & $* * 46,0$ & 100 \\
\hline Sindicato & 74,8 & 25,2 & 100 & 51,0 & 49,0 & 100 \\
\hline $\begin{array}{l}\text { Partidos políticos u Organizaciones } \\
\text { políticas }\end{array}$ & 48,7 & 51,3 & 100 & 59,7 & 40,3 & 100 \\
\hline $\begin{array}{l}\text { Asociación productiva (Microempresarios } \\
\text { Agrícola, Pescadores) }\end{array}$ & - & - & 100 & 61,1 & 38,9 & 100 \\
\hline Organización juvenil & 67,6 & 32,4 & 100 & 40,2 & 59,8 & 100 \\
\hline $\begin{array}{l}\text { Grupo religioso (Movimientos pastorales, } \\
\text { Grupo de iglesia) }\end{array}$ & 40,8 & 59,2 & 100 & 36,4 & 63,6 & 100 \\
\hline Organización de adultos mayores & 15,1 & 84,9 & 100 & 19,7 & 80,3 & 100 \\
\hline Agrupación o asociación indígena & - & - & - & 56,8 & 43,2 & 100 \\
\hline Comunidad o Grupo virtual & - & - & - & - & - & - \\
\hline Agrupación cultural o creación artística & 49,7 & 50,3 & 100 & 46,0 & 54,0 & 100 \\
\hline $\begin{array}{l}\text { Centro de madres, talleres de mujeres, } \\
\text { grupo de mujeres }\end{array}$ & 3,0 & 97,0 & 100 & 0,0 & 100,0 & 100 \\
\hline Asociación de personas con discapacidad & 59,2 & 40,8 & 100 & 42,9 & 57,1 & 100 \\
\hline
\end{tabular}

$(-)$ = INFORMACIÓN NO DISPONIBLE, PORQUE NO SE PREGUNTÓ SOBRE ESE TIPO DE ORGANIZACIÓN.

$(*)=$ ESTE PORCENTAJE SOLO INCLUYE PARTICIPACIÓN EN CENTROS DE PADRES Y APODERADOS.

$(* *)=$ ESTE PORCENTAJE SOLO INCLUYE COLEGIOS PROFESIONALES Y ASOCIACIONES GREMIALES

FUENTE ELABORACIÓN PROPIA EN BASE A DATOS OBTENIDOS DE: ENCUESTA CASEN 2000 Y CASEN 2009, MINISTERIO DE DESARROLLO SOCIAL, DIVISIÓN SOCIAL.

\section{Relación entre edad y participación en el Gran Santiago}

Otra pregunta que surge es si el nivel de participación difiere por tramo de edad. Es sabido que los jóvenes tienen niveles más bajos de participación en elecciones y otros procesos democráticos institucionalizados. En este respecto, ¿participan menos los jóvenes que los adultos también en el caso de asociaciones voluntarias? ¿Hay diferencias notorias en el nivel de participación según tramo de edad?

Al comparar los datos de las encuestas CASEN 2000 y CASEN 2009, aparece que la participación de la población en organizaciones sociales ha disminuido significativamente entre los años 2000 y 2009 (gráfico 7) ${ }^{15}$. Sin embargo, al comparar los tramos

15 Nota metodológica: para asimilar el universo de encuestados de CASEN a SCV, se seleccionan los encuestados de 18 años y más que habitan en el Gran Santiago. Se trabaja con las respuestas 
de edad entre sí, se observa una mayor participación de la población sobre 61 años, ventaja que persiste entre los años 2000 y 2009. Una posible explicación es que los adultos mayores tienen más tiempo para involucrarse y participar en organizaciones sociales y también pueden beneficiarse más de la socialización que ellas permiten y los servicios que ofrecen. Estos datos son coincidentes con los de la SCV 2013, que muestra que, en Santiago, 18,1\% de los adultos mayores de 61 ańos participa en alguna organización social, mientras que solo $11,6 \%$ de santiaguinos entre 46 y 60 años, $11,3 \%$ entre 30 y 45 años y 10,8\% entre 18 y 29 años son miembros de una organización social.

\section{GRÁFICO 7 | Participación en organizaciones sociales según tramo de edad (total Gran Santiago, población de 18 años y más)}

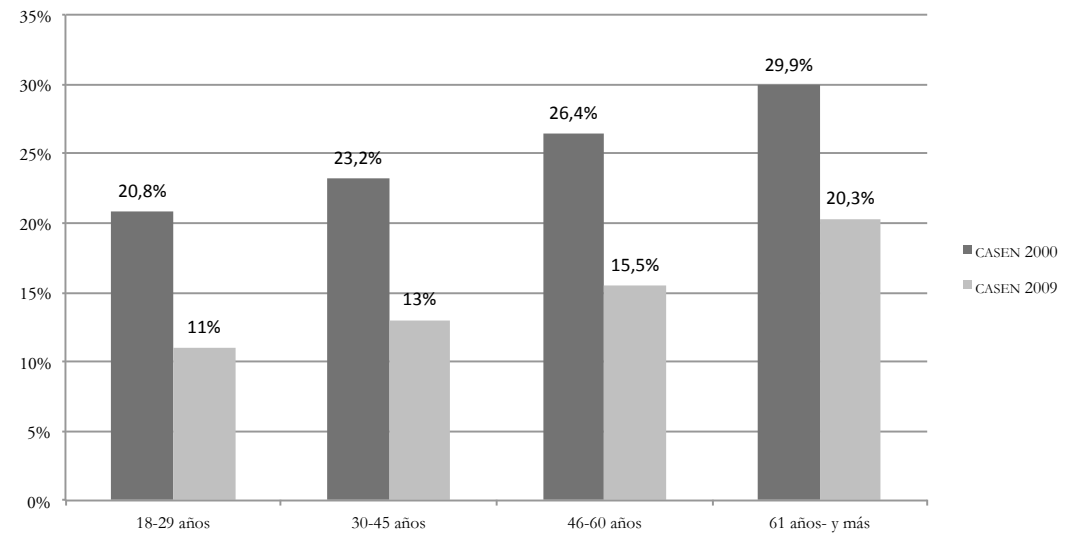

FUENTE ENCUESTAS CASEN 2000 Y CASEN 2009, MINISTERIO DE DESARROLLO SOCIAL, DIVISIÓN SOCIAL

\section{Participación ciudadana y planificación urbana en Chile y en el Gran Santiago}

La planificación urbana requiere de la participación activa de la ciudadanía: debe involucrarse a los ciudadanos cuyo territorio será planificado e intervenido no solo porque tienen el derecho a participar, por ser los principales usuarios y afectados, sino también porque poseen un conocimiento detallado sobre su propio hábitat (Herrmann, 2014). Se ha observado, además, que mientras mayor es la colaboración y participación activa de la ciudadanía en procesos de planificación urbana, mayor es la factibilidad de implementación de proyectos urbanos. Estudios internacionales muestran que la planificación activa otorga mayores incentivos para participar, dado que es más probable que los ciudadanos puedan ejercer mayor influencia

de las preguntas P18 (CASEN 2000) y T18A (CASEN 2009), esto es: ¿Participa usted en alguna de las siguientes organizaciones?, frente a la cual permiten elegir solo una respuesta entre todas las alternativas presentadas. Para obtener el porcentaje de respuesta "SÍ", se suman todos los encuestados que señalan haber participado en algún tipo de organización, y luego se clasifican por tramos de edad iguales a los estipulados por scv. 
y, por tanto, ver resultados. Es decir, la ciudadanía estaría más proclive a participar a medida que pueda incidir en las políticas públicas de forma más empoderada.

En Chile, el marco institucional y legal que regula la participación ciudadana en la planificación urbana es insuficiente. En el caso de la planificación urbana, los únicos instrumentos legales existentes de participación ciudadana son la Ley de Juntas de Vecinos (Ley 16880, Ley 20500), la participación ciudadana en la aprobación de planes reguladores comunales (Ley General de Urbanismo y Construcciones, Artículo 43) y la participación ciudadana en el sistema de evaluación de impacto ambiental (Ley 193000, sobre Bases Generales del Medio Ambiente) (Herrmann, 2014). Sin embargo, estas normas no han implicado un aumento en la capacidad de los individuos de influenciar las políticas que los afectan, sino que apuntan a establecer modalidades de consulta -la mayor parte de las veces sobre decisiones ya tomadas- o validación. De hecho, en Chile, las observaciones expuestas por la población no son vinculantes y solo deben ser ponderadas por la autoridad.

En respuesta a este problema, la reciente Política Nacional de Desarrollo Urbano chilena (PNDU) (MINVU, 2013) establece que la planificación urbana requiere de una participación ciudadana "efectiva". Especifica que la institucionalidad debe garantizar "dicha dimensión fundamental del desarrollo urbano sustentable" (pár. 5.4.1) y que la participación ciudadana debe ser institucionalizada, temprana, técnica y financiada, asegurando "acceso expedito a fondos públicos" (pár. 5.4.6), en línea con lo establecido en la Ley 20500 sobre participación ciudadana ${ }^{16}$ ). Con este fin, la PNDU propone tres modificaciones relevantes a la Ley General de Urbanismo y Construcciones: i) extender los procesos de participación a todos los Instrumentos de Planificación Territorial y no solo a los planes reguladores comunales; ii) incorporar la participación ciudadana en proyectos de infraestructura vial y transporte; y iii) asegurar que la ciudadanía cuente con todos los antecedentes de las propuestas (Nota explicativa 64). Asimismo, la PNDU estipula que se debe "fomentar y apoyar la participación y la creación de organizaciones de base en los barrios, comunidades y conjuntos, como instancias de integración social y desarrollo local” (pár. 1.6.3).

Pero ¿en qué tipo de organización social prefieren participar los chilenos y los santiaguinos?

Los tipos de organización que cuentan con niveles de participación más altos en Chile son los grupos religiosos, los clubes deportivos y las organizaciones de vecinos (cuadros 2 y 3). Si bien en el caso de los tipos de organización las diferencias metodológicas entre las encuestas CASEN y $\mathrm{SCV}^{17}$ no permiten cuantificar un aumento o una disminución entre los ańos 2009 y 2013, la sCv 2013 ratifica la preferencia de

16 Ley Núm. 20500 Sobre asociaciones y participación ciudadana en la gestión pública (febrero 2011), en http://www.leychile.cl/navegar?idnorma $=1023143$

17 Nota metodológica: como en el cuadro 1, en el caso de la encuesta CASEN 2000 se escogieron únicamente aquellas organizaciones sociales que se consideran más claves para entender cómo se distribuye la participación en organizaciones sociales. En el caso de la CASEN 2009 se considera únicamente la organización social que se menciona como la primera opción de organización preferente. En la SCV 2013, el encuestado podía señalar su participación en varias asociaciones voluntarias en el presente o pasado. Esta diferencia metodológica explica el aumento del porcentaje de población que participa en organizaciones sociales preferentes en la SCV 2013 (pregunta 34). 
la población por participar en clubes deportivos, grupos religiosos y organizaciones de vecinos. Cabe destacar que de estas tres organizaciones "preferentes", solo las organizaciones de vecinos (junta de vecinos y unión comunal) se involucran habitualmente en procesos de planificación urbana. Otras organizaciones sociales que históricamente han tenido incidencia en la definición de políticas urbanas, como los partidos políticos y las asociaciones gremiales, presentan muy bajos porcentajes de participación (partidos políticos: CASEN 2000, 0,5\%; CASEN 2009, 0,3\%).

\section{CUADRo 2 Distribución de la población que participa en organizaciones sociales según tipo de organización (Gran Santiago, población de 18 años y más)}

\begin{tabular}{|l|c|c|}
\hline \multicolumn{1}{|c|}{ TIPO DE ORGANIZACIóN PREFERENTE } & CASEN 2000 & CASEN 2009 \\
\hline Organización de vecinos (Junta de vecinos, Unión comunal) & $3,8 \%$ & $2,4 \%$ \\
\hline Club deportivo y recreativo & $5,1 \%$ & $2,2 \%$ \\
\hline Centro de alumnos, Centro de padres y apoderados & $* 0,8 \%$ & $0,5 \%$ \\
\hline Organización voluntariado o beneficencia & $0,6 \%$ & $0,7 \%$ \\
\hline Colegio profesional/Asociación gremial/Agrupación de empresarios & $0,3 \%$ & $* * 0,3 \%$ \\
\hline Sindicato & $0,2 \%$ & $0,9 \%$ \\
\hline Partidos políticos u Organizaciones políticas & $0,5 \%$ & $0,3 \%$ \\
\hline Asociación productiva (Microempresarios, Agrícola, Pescadores) & - & $0,1 \%$ \\
\hline Organización juvenil & $0,2 \%$ & $0,3 \%$ \\
\hline Grupo religioso (Movimientos pastorales, Grupo de Iglesia) & $9,0 \%$ & $4,0 \%$ \\
\hline Organización de adultos mayores & $0,8 \%$ & $1,1 \%$ \\
\hline Agrupación o asociación indígena & - & $0,0 \%$ \\
\hline Comunidad o Grupo virtual & - & - \\
\hline Agrupación cultural o creación artística & $0,6 \%$ & $1,1 \%$ \\
\hline Centro de madres, talleres de mujeres, grupo de mujeres & $0,9 \%$ & $0,5 \%$ \\
\hline Asociación de personas con discapacidad & $0,0 \%$ & $0,0 \%$ \\
\hline
\end{tabular}

$(-)$ = INFORMACIÓN NO DISPONIBLE, PORQUE NO SE PREGUNTÓ SOBRE ESE TIPO DE ORGANIZACIÓN.

$(*)=$ ESTE PORCENTAJE SOLO INCLUYE PARTICIPACIÓN EN CENTROS DE PADRES Y APODERADOS.

$(* *)=$ ESTE PORCENTAJE SOLO INCLUYE COLEGIOS PROFESIONALES Y ASOCIACIONES GREMIALES.

FUENTE ELABORACIÓN PROPIA A PARTIR DE DATOS OBTENIDOS DE ENCUESTAS CASEN 2000 Y CASEN 2009, MINISTERIO DE DESARROLLO SOCIAL, DIVISIÓN SOCIAL

La Política Nacional de Desarrollo Urbano establece específicamente que se deben reforzar las juntas de vecinos a nivel local, "dándoles el carácter de organizaciones territoriales y apoyando su quehacer con instancias de participación tanto en materias de planificación local como en el desarrollo de proyectos públicos locales" (MINvu, 2013, pár. 5.4.8). En Chile se crearon, entre 1964 y 1970, 3.487 juntas de vecinos y 9.000 centros de madres con 450.000 socias, construyéndose un fuerte vínculo entre las asociaciones comunitarias y la administración política municipal y central (Jiménez, 2012) ${ }^{18}$. Durante la dictadura, sin embargo - periodo en el cual los 
dirigentes vecinales fueron designados por las autoridades municipales-, las juntas de vecinos perdieron su relevancia. Al llegar la democracia, recuperaron el derecho a elegir a sus directivas y se restableció la facultad de las uniones comunales de juntas de vecinos para federarse a nivel provincial, regional y nacional (Ley 20500, de 2011). No obstante, hasta hoy las organizaciones vecinales no han recuperado el rol y la influencia que ejercían antes de la dictadura. De hecho, la encuesta CASEN muestra que la participación de los santiaguinos en organizaciones de vecinos ha disminuido en más de un tercio, de 3,8\% el año 2000 a 2,4\% en 2009. Asimismo, la SCV 2013 arroja que solamente el 26,5\% de los santiaguinos conoce a junta de vecinos de su barrio - mientras mayor es la población en edad, mayor es el conocimiento de la directiva de la junta de vecinos-, y la califica con una nota promedio de 5,12 (gráfico 8). Esto coincide con los datos analizados anteriormente, donde se establece que la participación en asociaciones sociales aumenta con la edad. Cabe destacar que en Chile han surgido durante el siglo xxi juntas de vecinos y uniones comunales que han desempeñado un rol importante en la oposición a proyectos territoriales, formando parte, por ejemplo, del Movimiento Social Freirina y del Movimiento Social Aysén y Magallanes.

CUADRO 3 | Participación en organizaciones sociales por tipo de organización preferente (Gran Santiago, población de 18 años y más, en porcentajes)

\begin{tabular}{|l|c|}
\hline \multicolumn{1}{|c|}{ TIPO DE ORGANIZACIÓN PREFERENTE } & SCV 2OI3 \\
\hline Organización de vecinos (Junta de vecinos, Unión comunal) & 9,3 \\
\hline Club deportivo y recreativo & 10,3 \\
\hline Centro de alumnos, Centro de padres y apoderados & 8,2 \\
\hline Organización voluntariado o beneficencia & 4,2 \\
\hline Sindicato, Colegio profesional o Asociación gremial & 3,3 \\
\hline Partidos políticos u Organizaciones políticas & 1,0 \\
\hline Asociación productiva (Microempresarios, Agrícola, Pescadores) & 0,8 \\
\hline Organización juvenil & 3,9 \\
\hline Grupo religioso (Movimientos pastorales, Grupo de Iglesia) & 8,3 \\
\hline Organizaciones ciudadanas (Indígena, Juvenil, Adulto Mayor, etcétera) & 3,1 \\
\hline Comunidad o Grupo virtual & 1,9 \\
\hline Agrupación cultural o creación artística & 2,7 \\
\hline
\end{tabular}

FUENTE SANTIAGO CÓMO VAMOS. PRIMERA ENCUESTA CIUDADANA 2OI 3. PERCEPCIÓN A LA GESTIÓN Y CALIDAD DE VIDA DE SANTIAGO

Con el objetivo de incidir en las políticas urbanas u oponerse a proyectos territoriales de alto impacto, se han creado en Chile, también desde fines de los años noventa, las denominadas "organizaciones ciudadanas", de carácter tanto "territorial” (p. ej. movimientos de rechazo a autopistas urbanas o a modificaciones de Planes Reguladores, etcétera) como "funcional" (p. ej. agrupaciones de ciclistas, 
medioambientales, etcétera) (Herrmann, 2014). De hecho, entre los años 1997 y 2008 se crearon más de treinta organizaciones ciudadanas con el propósito de objetar nuevas autopistas urbanas ${ }^{19}$ y corredores de transporte público, así como modificaciones a planes reguladores, rechazándose, por ejemplo, el aumento de la altura de edificación y la localización de nuevos centros comerciales (Poduje, 2008). Cabe señalar que estas "organizaciones ciudadanas" han frenado o mitigado las externalidades negativas de numerosos planes y proyectos territoriales (Herrmann, 2014). No obstante, los datos de la encuesta SCV arrojan que el porcentaje de población que participa en estas organizaciones ciudadanas es aún muy bajo, siendo en el año 2013 en la ciudad de Santiago de solamente 3,1\% (cifra incluye organizaciones juveniles, indígenas y de adulto mayor).

GRÁfico 8 | Conocimiento de la población sobre la directiva de la junta de vecinos según tramo de edad (Gran Santiago, población de 18 años y más)

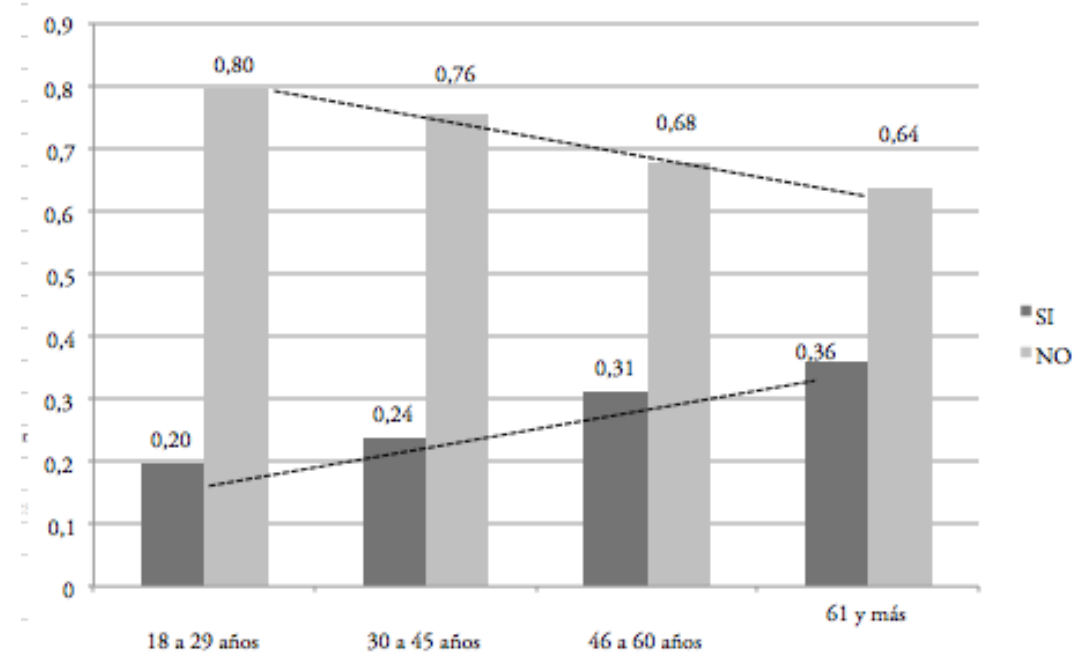

FUENTE ELABORACIÓN PROPIA A PARTIR DE DATOS OBTENIDOS DE SANTIAGO CÓMO VAMOS. PRIMERA ENCUESTA CIUDADANA 2OI3. PERCEPCIÓN A LA GESTIÓN Y CALIDAD DE VIDA DE SANTIAGO

\section{Pero ¿por qué los santiaguinos no participan en organizaciones sociales?}

Los datos arrojados por la encuesta SCV 2013 permiten ahondar en las motivaciones de los santiaguinos para participar en asociaciones voluntarias y las razones por las cuales muchos deciden no hacerlo. En la ciudad de Santiago, el ańo 2013 solamente un $12,4 \%$ de la población declaraba participar en organizaciones sociales. Como motivación principal para ello, los encuestados escogieron la respuesta "Otros" (50\%), seguida de "Por entretención" (15\%), "Necesitaba expresarme, dar mi opinión" (11\%), "Busco un beneficio personal o familiar" (7\%) y "Busco un cambio" (7\%) (gráfico 9).

19 El primer programa de concesiones de autopistas urbanas en la ciudad de Santiago originó en 1996 el movimiento "No a la Costanera Norte", que a su vez dio origen a "Ciudad Viva", una de las principales organizaciones comunitarias de Santiago. 


\section{GRÁFICO 9| Motivaciones principales para participar en organizaciones sociales (Gran Santiago, población de 18 años y más)}

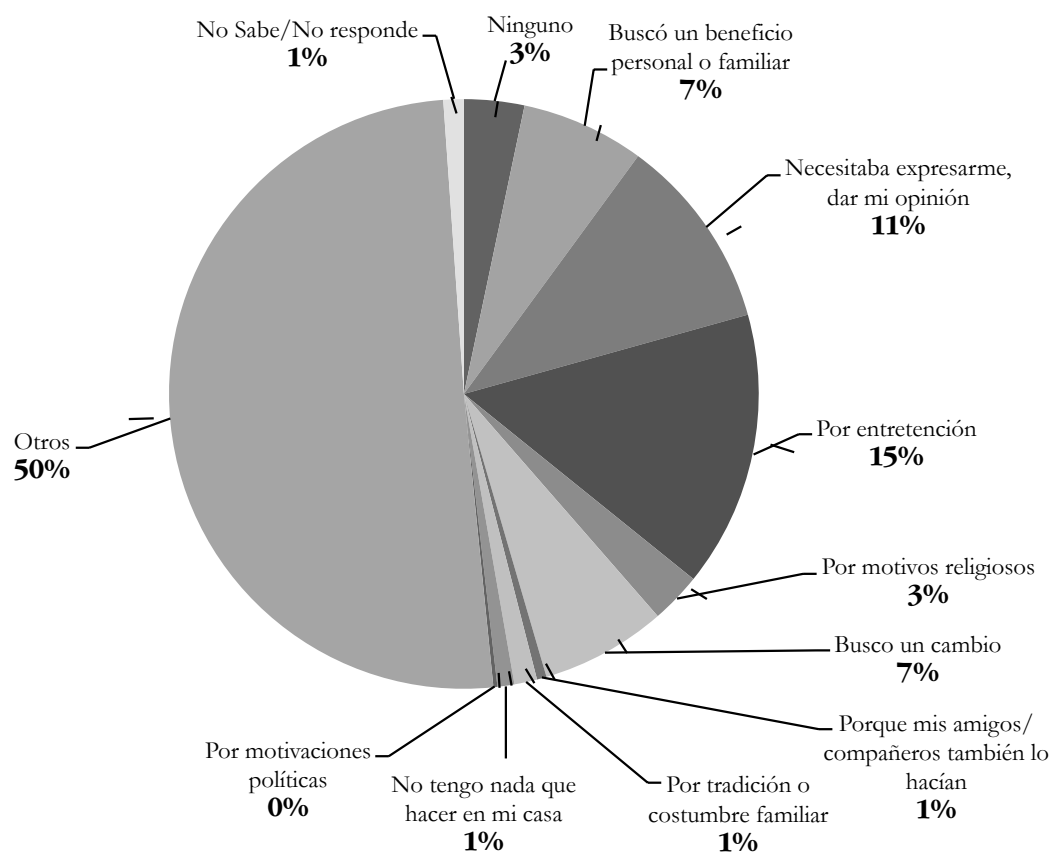

FUENTE SANTIAGO CÓMO VAMOS. PRIMERA ENCUESTA CIUDADANA 2OI3. PERCEPCIÓN A LA GESTIÓN Y CALIDAD DE VIDA DE SANTIAGO

Las razones por las cuales los santiaguinos, en cambio, declaran no participar en organizaciones sociales son principalmente la falta de tiempo (36\%) y falta de interés (30\%). La falta de interés destaca especialmente en el caso de los jóvenes entre 18 y 29 ańos (36,5\%), mientras que los adultos entre 30 y 60 años señalan como principal razón la falta de tiempo (30 a 45 años, 40,8\%; 46 a 60 años, $41,9 \%)$. La población manifiesta, además, que hay falta de información (12\%), que la participación en organizaciones sociales "no sirve de nada" (2\%), que desconfía de las organizaciones sociales $(2 \%)$ o que no le ha sido necesario participar en una asociación voluntaria (4\%) (gráfico 10). 
GRÁfICo ro | Razones por las cuales la población no participa en organizaciones sociales (Gran Santiago, población de 18 años y más)

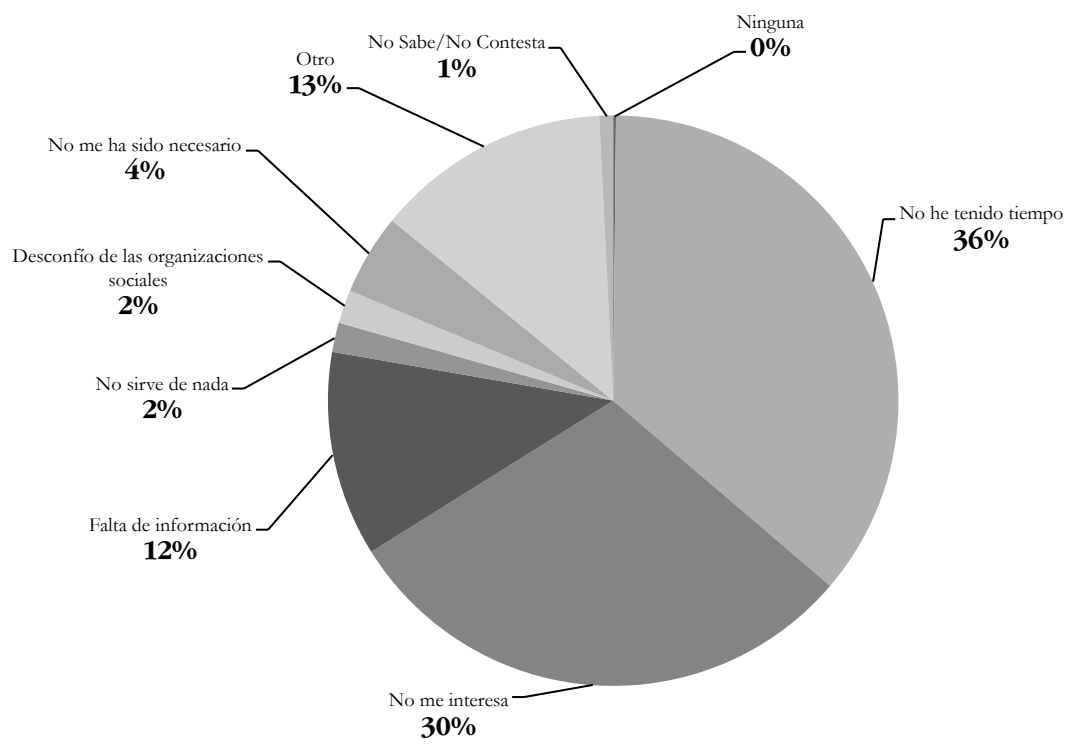

FUENTE SANTIAGO CÓMO VAMOS. PRIMERA ENCUESTA CIUDADANA 2OI3. PERCEPCiÓN A LA GESTIÓN Y CALIDAD DE VIDA DE SANTIAGO

Y ¿̨uál es la percepción de los santiaguinos frente a instrumentos de planificación urbana participativa?

Los santiaguinos perciben que la ciudadanía tiene poca incidencia en la toma de decisiones de políticas urbanas, lo que puede afectar negativamente sus motivaciones para participar. Al ser preguntados quién dirige la ciudad de Santiago, los ciudadanos señalan en su mayoría a alcaldes (44\%) e intendentes (20\%) (scv, 2013). La ciudadanía, en cambio, es percibida tan solo por $13 \%$ de los encuestados como actor dirigente. Además, la scv 2013 arroja que un 51\% de los santiaguinos opina que la participación ciudadana en la toma de decisiones no es bien recibida, mientras que solo $38 \%$ piensa que sí hay una buena recepción.

Sorprendentemente, los santiaguinos tampoco tienen una percepción positiva frente a instrumentos que permitirían a la ciudadanía participar de forma más activa en la toma de decisiones urbanas. Ante la pregunta de si consultar a la ciudadanía o convocar a un grupo de expertos para decidir distintos tipos de planes comunales -Plan Regulador Comunal, Plan de Desarrollo Comunal, Plan de Transporte y Movilidad, Declaración de Zonas Patrimoniales, Presupuesto Comunal, Plan de Inversión Comunal-, los ciudadanos prefieren convocar a un grupo de expertos (scv, 2013) (cuadro 4). De hecho, frente a un cambio de Plan Regulador Comunal, un $47 \%$ de los ciudadanos escoge convocar a un grupo de expertos y un $40 \%$ prefiere hacer un plebiscito. En el caso de los Planes de Transporte Comunal, esta diferencia es aún más exacerbada: el 59\% de los ciudadanos prefiere convocar a un 
grupo de expertos y solamente un $28 \%$ opta por realizar un plebiscito, pese a que la movilidad y congestión son preocupaciones importantes de los santiaguinos según la SCV 2013.

En general, un $55 \%$ de los santiaguinos piensa que un plebiscito comunal no funciona, un $28 \%$ no sabe/no contesta y solamente un $17 \%$ de los ciudadanos considera que un plebiscito comunal funciona. Asimismo, solamente un 10\% de los santiaguinos ha escuchado hablar sobre el Consejo Comunal de la Sociedad Civil y un $81 \%$ lo desconoce (scv, 2013).

CUADro 4 | Preferencia de la ciudadanía por plebiscitos o grupos de expertos como mecanismo en la toma de decisión de políticas urbanas (Gran Santiago, población de 18 años y más, en porcentajes)

SI LAS AUTORIDADES TUVIERAN QUE DECIDIR ENTRE CONSULTAR A LA CIUDADANÍA O CONVOCAR A UN GRUPO DE EXPERTOS, ¿QUÉ DEBERÍAN HACER PARA DECIDIR...?

\begin{tabular}{|l|c|c|c|c|}
\cline { 2 - 5 } \multicolumn{1}{c|}{} & $\begin{array}{c}\text { HACER UN } \\
\text { PLEBISCITO }\end{array}$ & $\begin{array}{c}\text { CONVOCAR } \\
\text { A UN GRUPO } \\
\text { DE EXPERTOS } \\
\text { PARA DECIDIR }\end{array}$ & NS/NC & NINGUNO \\
\hline Cambiar el plano regulador de su comuna & 39,8 & 47,0 & 11,1 & 2,0 \\
\hline Autorizar el presupuesto de su comuna & 35,9 & 52,0 & 10,1 & 2,0 \\
\hline Discutir el plan de desarrollo comunal & 35,4 & 50,2 & 12,0 & 2,3 \\
\hline Planes de transporte y movilidad comunal & 28,0 & 58,9 & 10,9 & 2,2 \\
\hline Plan de inversiones comunal & 28,6 & 57,8 & 11,7 & 1,9 \\
\hline Declaración de zonas patrimoniales & 22,7 & 63,9 & 11,2 & 2,2 \\
\hline
\end{tabular}

FUENTE SANTIAGO CÓMO VAMOS. PRIMERA ENCUESTA CIUDADANA 2OI 3. PERCEPCIÓN A LA GESTIÓN Y CALIDAD DE VIDA DE SANTIAGO (P. 5I)

Otro instrumento importante de planificación urbana participativa es el Presupuesto Participativo Comunal. Los presupuestos participativos fueron iniciados en Porto Alegre, Brasil, a principios de los noventa por el Partido de los Trabajadores. El objetivo era crear un espacio para que los ciudadanos pudieran contribuir substantivamente en los procesos de toma de decisiones a nivel municipal. Los presupuestos participativos dieron lugar a una estructura de asambleas en cada uno de los 16 distritos de Porto Alegre, y combinaban elementos de democracia directos y representativos (Baiocchi, 2003, p. 53). También han sido desarrollados en muchas ciudades latinoamericanas, en países como Perú, Ecuador y Colombia, entre otros. A pesar de que las modalidades específicas, los fondos considerados, el grado de institucionalidad y la sustentabilidad del proceso varían de experiencia a experiencia, los presupuestos participativos son mecanismos innovadores para el ejercicio de la democracia a nivel local (Cabannes, 2004, p. 27).

En Chile, sin embargo, la población señala no tener interés en participar en presupuestos participativos. Así, la scv 2013 arroja que 75\% de los santiaguinos no participaría en un presupuesto participativo comunal, $2 \%$ no sabe o no contesta y solamente un $23 \%$ de la población estaría interesada en hacerlo. Estos indicadores 
muestran una falta de interés e incluso desconfianza de la ciudadanía chilena hacia mecanismos que permiten una participación más directa de la población en la toma de decisiones urbanas, lo que plantea un fuerte desafío para la construcción de una política de planificación urbana más participativa en Chile.

\section{Conclusiones}

Disminución de la participación de la población en organizaciones sociales durante los últimos trece años en Chile

Se ha enfatizado que se necesitan en Chile nuevos instrumentos de planificación urbana que permitan una interacción constructiva entre el sector público, el sector privado y una ciudadanía activa capaz de incidir en las políticas públicas urbanas (Greene \& Soler, 2004; Ducci, 2004). En línea con esto, la reciente Política Nacional de Desarrollo Urbano en Chile establece que la planificación urbana requiere de una participación ciudadana "efectiva", entendida como "una condición proactiva” que debe ser garantizada por la institucionalidad (MINvU, 2013, pár. 5.4.2). Sin embargo, esta investigación muestra que la participación de la población en asociaciones voluntarias ha disminuido significativamente en Chile en general, y en el Gran Santiago en particular. Al analizar comparativamente las encuestas CASEN 2000, CASEN 2009 y SCV 2013, este artículo arroja que la participación de la población en organizaciones sociales en la ciudad de Santiago ha disminuido del $23,8 \%$ al $12,4 \%$ durante el siglo XXI, reduciéndose en solo trece ańos a casi la mitad.

Una razón para lo anterior puede ser el impacto que tuvo la dictadura en las organizaciones sociales, ya que se ha establecido que un nivel elevado de estabilidad democrática brinda más tiempo para que las asociaciones se desarrollen y consoliden, y para que los ciudadanos desarrollen mayor confianza entre sí, lo que puede traducirse en mayor participación, cooperación y reciprocidad. Otra razón relacionada es el impacto que puede haber tenido la implementación de un sistema neoliberal, el cual promueve una lógica individualista que deja poca cabida a la participación social en diferentes organizaciones. Tradicionalmente y como se ha abordado en este artículo, la participación en Chile se ha incentivado de una manera muy limitada y siguiendo una lógica de validación o consulta, donde existen pocas oportunidades e incentivos para los ciudadanos de involucrarse sustantivamente. El argumento de Arnstein (1969) -formulado hace ya más de cincuenta años y basado en el análisis de programas comunales participativos en los Estados Unidos- se aplica a la participación ciudadana en la planificación urbana del Chile de hoy: a pesar del aumento progresivo de programas públicos de participación ciudadana, esta no es bien entendida y se suele centrar en las categorías de no participación o donde la participación es simbólica. Como resultado, estos programas públicos no logran fomentar el empoderamiento ciudadano, observándose hoy en Chile una falta de interés, e incluso una desconfianza de la población frente a mecanismos que permitirían una participación más directa de la ciudadanía en la toma de decisiones urbanas.

En Chile existen, por tanto, trabas estructurales que han influido en el nivel de participación y en la percepción que de ella tienen los ciudadanos. Al respecto, es interesante observar el nuevo auge de movimientos sociales y organizaciones 
ciudadanas (de estudiantes, territoriales, medioambientales, etcétera) y el impacto demostrativo que pueden tener sobre la participación en organizaciones sociales y en la planificación urbana en general.

Otras conclusiones de esta investigación son las siguientes:

- Contrario a teorías académicas internacionales, en Chile el nivel de ingreso no cumple una función en el grado de participación de la población en organizaciones sociales: el porcentaje de participación es muy homogéneo a través de los distintos grupos socioeconómicos y ha declinado significativamente durante los últimos trece años en todos los quintiles.

- En relación con el factor edad, se observa en Chile una participación más alta en la población mayor de 61 años y una falta de interés en los jóvenes en cuanto a participar en asociaciones voluntarias.

- Se comprueba en Chile una diferencia en el tipo de organización en que participan hombres y mujeres. El nivel de participación de hombres es considerablemente mayor al de mujeres en organizaciones influyentes (como sindicatos, asociaciones gremiales y partidos políticos), mientras que las mujeres participan en mayor medida en organizaciones de orientación comunitaria.

- En general, se observa en Chile una preferencia de la población por participar en clubes deportivos, grupos religiosos y organizaciones de vecinos. En cambio, ha declinado significativamente la participación de la población en partidos políticos, sindicatos y asociaciones gremiales.

- Por último, resalta la falta de interés y la desconfianza de la ciudadanía hacia instrumentos que le permitirían una participación más activa en la definición de políticas urbanas. De hecho, en la ciudad de Santiago la población prefiere convocar a un grupo de expertos que llamar a un plebiscito como mecanismo de toma de decisión, y 75\% de los santiaguinos declara que no participaría en un presupuesto participativo comunal.

Implicaciones para la construcción de una política de planificación urbana más participativa

La planificación urbana requiere de la participación activa de la ciudadanía. Sin embargo -como señala este artículo-, se observa en Chile una falta de interés de la ciudadanía por participar en organizaciones sociales y en mecanismos de planificación urbana participativa.

Se ha mostrado que la planificación activa otorga mayores incentivos para participar, dado que es más probable que los ciudadanos puedan ejercer mayor influencia y, por tanto, ver resultados. En consecuencia, el Estado y las municipalidades deben promover el empoderamiento de la ciudadanía a partir de instrumentos de planificación urbana participativa y desarrollar nuevos instrumentos para el ejercicio de la democracia a nivel local. Ejemplo de ellos son presupuestos participativos que permitan transitar desde una participación simbólica hacia otra que otorgue a los ciudadanos la posibilidad de ejercer influencia directa en aquellas decisiones que más los afectan. Asimismo, en un país altamente centralizado como Chile, es esencial 
que se fortalezcan aquellas organizaciones sociales "territoriales" que puedan reflejar mejor las prioridades a esa escala. En Chile, la más institucionalizada y consolidada es la Junta de Vecinos, la cual debería constituirse en un actor clave en los procesos de planificación urbana.

Por último, el Estado debe proveer más financiamiento a las municipalidades para la formación de asociaciones, como una forma de fomentar la cohesión social y crear un espacio en el que los ciudadanos puedan contribuir substantivamente en los procesos de toma de decisiones relativas al ámbito urbano -y también en otros-a nivel municipal. En este sentido, resulta alentador que la reciente Política Nacional de Desarrollo Urbano en Chile seńale expresamente que la participación ciudadana debe ser institucionalizada, temprana y financiada, con acceso seguro y expedito a fondos públicos que permitan su funcionamiento e independencia (MINVU, 2013, pár. 5.4.6). Es probable que así, paulatinamente, se avance hacia una noción de la democracia más integral, centrada en cómo los ciudadanos la experimentan en su día a día, y no únicamente en el ejercicio de voto durante una elección.

\section{Referencias bibliográficas}

Aguilar, F. \& Navarro, J. C. (2000). Democracia y participación ciudadana en los municipios: ¿un mercado político de trastos? Revista Española de Investigaciones Sociológica (REIS) [en línea], (91/100), 89-111. En http://www.redalyc.org/comocitar.oa?id=99717878004

Almond, G. A. \& Verba, S. (1963). The civic culture: Political attitudes and democracy in five nations. Newbury Park, CA: Sage.

Arnstein, S. (1969). A ladder of citizen participation. Journal of the American Institute of Planners, 39(4), 216-224. doi: 10.1080/01944366908977225

Baiocchi, G. (2003). Emergent public spheres: Talking politics in participatory governance. American Sociological Review, 68(1), 52-74. doi: 10.2307/3088902

Cabannes, Y. (2004). Participatory budgeting: A significant contribution to participatory democracy. Environment \& Urbanization, 16(1), 27-46. doi: $10.1177 / 095624780401600104$

Cohen, J. \& Rogers, J. (1992). Secondary associations and democratic governance. Politics and Society, 20(4), 393-472. En http://pas.sagepub.com/content/20/4/393.extract

Curtis, J. E., Baer, D. E. \& Grabb, E. G. (2001). Nations of joiners: Explaining voluntary association membership in democratic societies. American Sociological Review, 66(6),783-805. doi: 10.2307/3088873

Diani, M., Edwards, B. \& Foley, M. W. (2001). Beyond Tocqueville: Civil society and the social capital debate in comparative perspective. Hanover: University Press of New England.

Ducci, M. E. (2004). Las batallas urbanas de principios del tercer milenio. En C. de Mattos, M. E. Ducci, A. Rodríguez \& G. Yáñez Warner (Eds.), Santiago en la globalización: ¿Una nueva ciudad? (pp. 137-166). Santiago: Ediciones sur/Eure Libros. 
Encuesta Santiago Cómo Vamos. Primera Encuesta Ciudadana 2013. Percepción a la gestión y calidad de vida de Santiago. Santiago: Laboratorio Ciudad y Territorio (LCT), Universidad Diego Portales (Udp)/ong Ciudad Viva/Fundación Avina. Publicada 15 marzo 2013. En http://www.drcom.udp.cl/encuesta_LCT2013.pdf

Font, J., Blanco, I., Gomá, R. \& Jarque, M. (2000). Mecanismos de participación ciudadana en la toma de decisiones locales: una visión panorámica. Serie Documentos Debate, Centro Latinoamericano de Administración para el Desarrollo (CLAD). xiv Concurso de Ensayos del clad "Administración Pública y Ciudadanía" (pp. 113-140). Publicado en Revista ONSC (Oficina Nacional del Registro Civil, Uruguay, 2012), 7(50), 102-131. En http://www. onsc.gub.uy/onsc1/images/stories/Publicaciones/RevistaONSC/r50/50_11.pdf

Fung, A. (2003). Associations and democracy: Between theories, hopes, and realities. Annual Review of Sociology, 29, 515-539. doi: 10.1146/annurev.soc.29.010202.100134

Greene, M. \& F. Soler. (2004). Santiago: De un proceso acelerado de crecimiento a un proceso de transformaciones. En C. de Mattos, M. E. Ducci, A. Rodríguez \& G. Yánez Warner (Eds.), Santiago en la globalización: ¿Una nueva ciudad? (pp. 47-84). Santiago: Ediciones SUR/EURE Libros.

Guijt, I. \& Shah, M. K. (1998). The myth of community: Gender issues in participatory development. Londres: Intermediate Technology Publications.

Herrmann, G. (2014). Hacer Ciudad: Problemas y desafíos de la participación ciudadana en la planificación territorial de Santiago. Revista 180, 18(34), 36-41.

Janoski, T. (1998). Citizenship and civil society. Cambridge: Cambridge University Press.

Jiménez, A. (2012). Día Nacional del Dirigente Vecinal y Comunitario. Borrador no publicado.

Lipset, S. (1994). The social requisites of democracy revisited: 1993 Presidential address. American Sociological Review, 59(1), 1-22. doi: 10.2307/2096130

Lister, R. (1998). Citizenship on the margins: Citizenship, social work and social action. European Journal of Social Work, 1(1), 5-18. doi: 10.1080/13691459808414719

Marshall, T. H. (2009). Citizenship and social class. En J. Manza \& M. Sauder (Eds.), Inequality and society (pp. 148-154). Nueva York: W.W. Norton and Co. Original en Citizenship and social class and other essays (pp. 1-85). Londres: Cambridge University Press, 1950; versión digitalizada en http://bit.ly/1G2BoJT

McAdam, D., Tarrow, S. \& Tilly, C. (2001). Dynamics of contention. Nueva York: Cambridge University Press.

Ministerio de Vivienda y Urbanismo (minvu), Chile. (2013). Política Nacional de Desarrollo Urbano. Ciudades sustentables y calidad de vida. Santiago: MINvu. En http://www. mtt.gob.cl/wp-content/uploads/2014/03/Pol\%C3\%ADtica-Nacional-de-DesarrolloUrbano-2013.pdf

Mohan, G. \& Stokke, K. (2000). Participatory development and empowerment: The dangers of localism. Third World Quarterly, 21(2), 247-268. doi: 10.1080/01436590050004346

Nelson, N. \& Wright, S. (1995). Power and participatory development: Theory and practice. Londres: Intermediate Technology Publications.

Poduje, I. 2008. Participación ciudadana en proyectos de infraestructura y planes reguladores. Temas de la Agenda Pública (P. Universidad Católica de Chile), 3(22). En https:// repositorio.uc.cl/bitstream/handle/11534/1521/514662.pdf?sequence $=1$

Putnam, R. D. (2000). Bowling alone: The collapse and revival of American community. Nueva York: Simon \& Schuster. 
Putnam, R. D., Leonardi, L. \& Nanetti, R. (1993). Making democracy work: Civic tradition in modern Italy. Princeton, NJ: Princeton University Press.

Schlozman, K. L., Burns, N., Verba, S. \& Donahue, J. (1995). Gender and citizen participation: Is there a different voice? American Journal of Political Science, 39(2), 267-293. doi: $10.2307 / 2111613$

Tocqueville, A. [1835-1840] (2000). Democracy in America. Traducido y editado por H. C. Mansfield \& D. Winthrop. Chicago y Londres: The University of Chicago Press.

Uslaner, E. M. \& Brown, M. (2005). Inequality, trust, and civic engagement. American Politics Research, 33(6), 868-894. doi: 10.1177/1532673X04271903

Verba, S., Schlozman, K. L. \& Brady, H. E. (1995). Voice and equality: Civic voluntarism in American politics. Cambridge, MA: Harvard University Press.

World Bank. (1994). The World Bank and participation. Washington, D.c.: The World Bank, Operations Policy Department, septiembre 1994. [Publicación autorizada]. En http://documentos.bancomundial.org/curated/es/1994/09/735083/world-bankparticipation 
